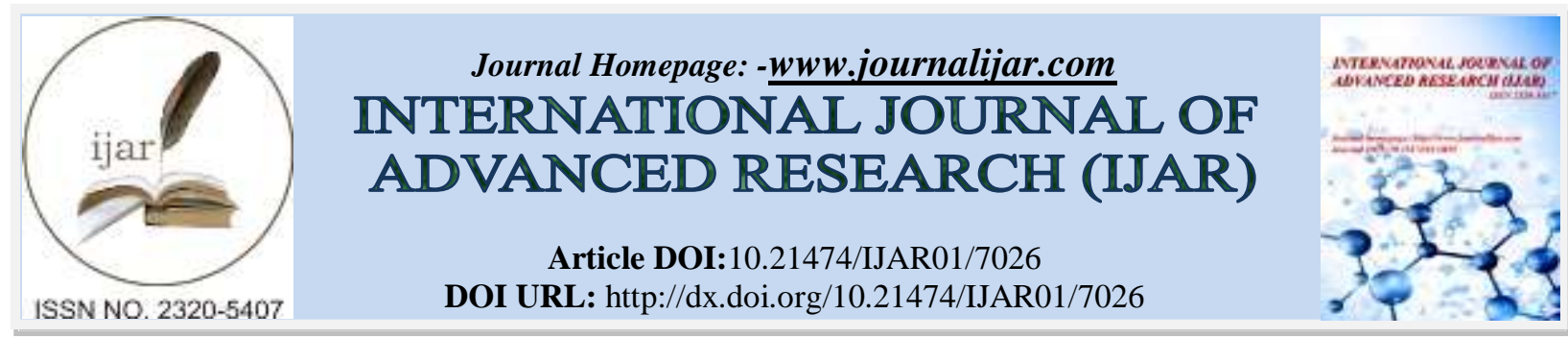

RESEARCH ARTICLE

\title{
COGNITIVE DRILL THERAPY IN MENTAL CONTAMINATION: A CASE STUDY.
}

\section{Sumaiya Khan ${ }^{1}$, Dr. Dinesh Singh Rathor ${ }^{2}$ and Dr. Rakesh Jain ${ }^{3}$.}

1. Students MPhil. Clinical Psychology, Department of Clinical Psychology, Institute of Mental Health and Hospital, Agra, India.

2. M.D., Associate Professor of Psychiatry, Department of Psychiatry, Institute of Mental Health and Hospital, Agra, India.

3. Senior Clinical Psychologist, Department of Clinical Psychology, Institute of Mental Health and Hospital, Agra, India.

\section{Manuscript Info}

Manuscript History

Received: 04 March 2018

Final Accepted: 06 April 2018

Published: May 2018

Keywords:-

Cognitive Drill Therapy OCD, Mental Contamination, Exposure and Response Prevention.

\section{Abstract}

Cognitive Drill Therapy (CDT) relies on repetitive verbal exposure of ideations related to feared consequences for psychological management of OCD and phobia. We are presenting a case of OCD with predominantly compulsive type who was having prominent features of mental contamination. He is a middle aged married male having his own professional law practice. His contamination OCD got triggered about two years back after gall bladder operation. He was being treated with SSRI for a few months. He was referred for psychological management. The severity ratings on Y-BOCS measure was 43 . His OBSD consisted of a large number of dirty objects; either touch or even being in proximity of dirty objects elicited severe distress in him leading to compulsive cleaning and washing his hands/body, clothes and objects; also he tended to avoid exposure to dirty objects by restricting his professional activities and going outside. The primary danger ideation was fear of spreading contamination to other objects in his house and work place. He was psychoeducated regarding his disorder and the role of feared cognition and compulsive acts in the maintenance of his compulsive behavior. Cognitive drill was applied in-vitro and at verbal level. No in-vivo behavioral exposure was done in therapy sessions. Typically, he was required to make his hands/body dirty in imagination and then mentally touch domestic objects and keep verbalizing that the touched object has become dirty. He demonstrated substantial reduction in his compulsive behaviors within six therapy sessions which were being maintained on two weeks and then six weeks follow up. More follow ups are being conducted. His Y-BOCS severity rating dropped substantially. There is a tremendous improvement in his socio-occupational functioning as well as perceived self-efficacy. The improvement is also validated by the reports of his family members. It is implicated that in-vitro and verbal exposure can ease the exposure task for the patients as well as the therapists. 


\section{Introduction}

Obsessive compulsive disorder is depicted by varied symptoms that include intrusive thoughts, preoccupations, rituals and compulsions (Sadock, Sadock \& Ruiz, 2015). Obsessive-compulsive disorder (OCD) is a highly researched and conceptualized disorder, and yet it remains one of the most incapacitating, extensive, and expensive disorders one can be troubled with (Real, Labad, Alonso, Segalas, Jimenez-Murcia, Bueno, Subirà, Julio Vallejo \& Menchon, 2011). Over the precedent three decades, obsessive-compulsive disorder (OCD) has stirred from an almost fatal, lifetime psychiatric disorder to a highly manageable one. The psychological treatment of obsessivecompulsive disorder (OCD) with exposure and response prevention (ERP) technique is one of the enormous achievement stories within the domain of mental health, with the most empirical support for its efficacy. However, over the years a number of relatively common therapist issues that decrease the efficacy of ERP have been noted (Gillihan, Williams, Malcoun, Yadin and Foa, 2012). It has also been observed that such dealings could provoke enormous amount of distress in the individuals. We applied a modestly aversive form of behavioral intervention which is termed as cognitive drill therapy (CDT) in a case of OCD predominantly compulsive type.

Mental contamination is a phenomenon by which people encounter feelings of defilement from a non-physical contaminant (Warnock-Parkes, Salkovskis, \&Rachman, 2012). Lot of patients with obsessive-compulsive disorder (OCD) reports this symptom. OCD perturbs between $1 \%-2.5 \%$ of the populace, with contamination distress and the associated compulsion to ablution excessively in a reported 38-50\% of people diagnosed with this disorder (Torres et al., 2006; Rachman\& Hodgson, 1980; Foa et al., 1995; Foa et al., 1998).

Cognitive Drill therapy is a recently developed therapy by Dr. Rakesh Kumar Jain (2012) for the effective management of situation and stimulus bound anxiety symptoms and disorders. This is a new therapy derived from the background of cognitive behavior therapy. The theoretical base of the CDT is conditioning, exposure, cognitive appraisal and linguistic pattern of anxiety disorders, specifically for phobia and OCD (Kumar and Dubey, 2016). The first step in CDT is to list thoughts/stimuli of threat perception and its time frame is converted from future to past/present. Further, the affected person is required to keep on verbally or sub-vocally repeating (called drill) the converted thoughts. A periodic body-mind reaction rating is procured on a scale of 0-100, since verbal exposure in this form can elicit mild to severe BMR. With continued repetitions, the affected person experiences spiky drop in fear reactions and BMR within a few minutes.

It is hypothesized that affected person is stuck in the top layer consisting of first three components. The affected person rarely confronts the threat perception which is classified as bottom layer. Perseverance of distorted threat perception sustains the anxiety reaction; hence, if we tackle this bottom layer directly in the therapy it would lead to speedy and extensive improvement in the anxiety reactions. We are presenting a case in which OCD predominantly compulsive type who was having prominent features of mental contamination, was treated by using CDT in this paper.

\section{Case summary}

Mr. X, a middle aged married male belonging to urban area having his own professional law practice presented with chief complaints of repetitive thoughts about being contaminated by dirty objects and transmitting it to others, increased anxiety and compulsive behavior. His illness stretched over for a total duration of 2 years. His contamination OCD got triggered about two years back after gall bladder operation, following which it was noticed that he started spending much of the time in cleaning his body or cloths if it touched or even in close proximity of any dirty object. He would not touch any other object or person in his house fearing that he would transmit the germs or illness onto the other person. He was being treated with SSRI for a few months. His OBSD consisted of a large number of dirty objects; either touch or even being in proximity of dirty objects elicited severe distress in him leading to compulsive cleaning and washing his hands/body, clothes and objects; also he tended to avoid exposure to dirty objects by restricting his professional activities and going outside. Eventually, his contamination OCD resulted in deterioration in his personal and socio-occupational functioning; following which he was referred for psychological management. 


\section{Cognitive Drill Therapy conceptualization:}

\section{$\mathrm{O}=$ object of fear}

It relates to all objects/situations that trigger anxiety reaction e.g. closed places, insects, animals, crowd etc.

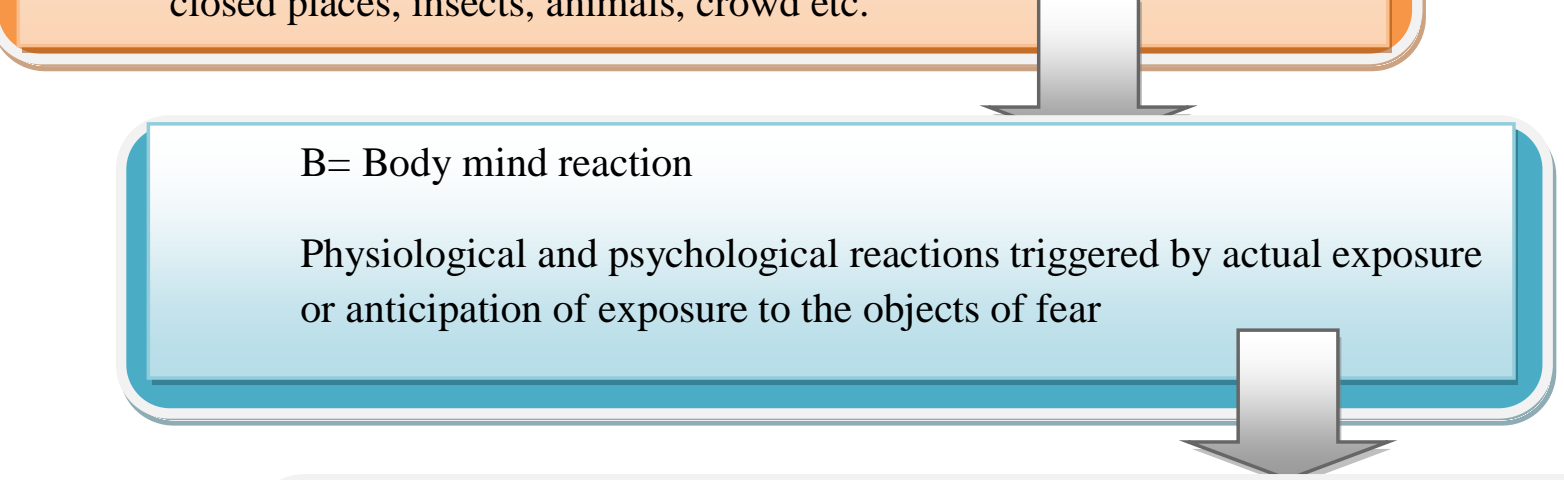

$\mathrm{S}=$ Safety behaviors

The pattern of avoidance or measures taken to curb the anxiety reactions

Pre therapy assessment:-

Pre-therapy assessment tools used

1. Yale-Brown Obsessive-Compulsive Scale (Y-BOCS)

2. The Vancouver Obsessional Compulsive Inventory -Mental Contamination Scale (VOCI-MC)

3. Sheehan Disability Scale (SDS)

\section{Assessment findings:-}

The Yale-Brown Obsessive-Compulsive Scale (Y-BOCS) is a widely used instrument to assess obsessivecompulsive symptomatology. On this scale patient's score on obsession subscale was 20, which indicates moderate range of severity and his score on compulsion subscale was 23, indicating moderate range of severity.

The Vancouver Obsessional Compulsive Inventory -Mental Contamination Scale (VOCI-MC) is a 20-item selfreport questionnaire designed to assess symptoms of mental contamination. Patient obtained a score of 65 which is quite high, with higher score indicating higher levels of mental contamination. The Sheehan Disability Scale (SDS) was developed to assess functional impairment in three inter-related domains; work/school, social and family life. Patient obtained a score of 5 in work/school domain, 7 in social domain and 8 in family domain. His global functioning impairment summed to be 20 , indicating moderate impairment.

\section{CDT formulation of present case}


$\mathrm{O}=$ Object of Fear

\section{Getting contaminated by any dirty object and transmitting it to others}

\begin{tabular}{|c|}
\hline B= Body Mind Reactions \\
\hline Irritability, anxiety, sweating \\
$\qquad$ S= Safety Behavior \\
\hline Doing ritualistic behaviors, reassurance, avoidance \\
\hline D= Danger Thoughts \\
I might get contaminated from dirty objects, if i touch other objects \\
they also might get contaminated, I might spread this contamination \\
onto others
\end{tabular}

\section{OBSD analysis}

OBSD analysis (Jain, 2016) was carried out to recognize objects that are allied with OCD, body-mind reactions brought forth by an exposure to the objects of anxiety, safety behaviors manifested by avoidance and compulsions and the apparent feared outcome.

1. Object of fear: A list of all the objects that he thinks would contaminate him was prepared. It included a wide range of objects including objects within his home and outside. For example, home objects included - wash basin, mop, garbage, etc and external objects included- car tires, dustbins, sweepers cart, drainage water, etc. Along with this he was also fearful of human and animal feces, urine or spit.

2. Body mind reactions: It was noticed that just an imagination of feared objects could lead to Severe BMR in the patient, indicated by irritation, anxiety, sweating, etc.

3. Safety behaviors: Indulging in compulsive behavior of cleaning the contaminated object and getting reassurance from family members, avoid going close to feared objects and restricting going out of his home. 
4. Danger thoughts: following thoughts of danger ideation were identified-

a. He might get contaminated with a dirty object

b. If he touches other objects they might also get contaminated

c. He might spread this contamination onto his family members

\section{Cognitive Drill therapy therapeutic package}

Cognitive drill therapy was implemented to the patient in eight sessions. In these sessions client's detailed case history and mental status examination was taken. Major areas of difficulty were identified from the informant as well as the client. Assessments were done to get a baseline measure of the intensity of current problems. The measure of subjective unit of distress was taken (10/10) at the beginning of the session and intensity of problems were rated by the client

\section{Psychoeducation}

Psychoeducation is one of the most important steps in any therapy as it prepares the patient for the therapy, by clearing all his doubts and inhibitions, and creates an insight within the patient that increases probability of success. A definite diagnosis of obsessive compulsive disorder predominantly compulsive type was given to him. Further, patient was psychoeducated about the connection between the functional nature of conditioned stimuli (triggers) in obsessive compulsive disorder and its reaction (fear, anxiety). Along with that the characteristic features of anxiety curve during the exposure to the feared objects, were also explained to him. OBSD framework was explained to the patient. He was explained about the top layer and the bottom layer cognitions and the cognitions that consist of future reference. He was introduced and explained about the term drill by taking examples from his cognitions. He was educated about how his BMR will shoot up when he would be verbalizing drill, but with repeated verbal exposure its severity will drop down. He was also informed about reactive inhibition and how it takes place.

\section{Drill statements}

Drill statements were prepared analogous to his danger thoughts. Patient was asked to identify and make a comprehensive list of objects of fears, body-mind reactions, safety behaviors and danger thoughts. Drill statements were prepared by changing the time frame of the danger thoughts. The future time reference was converted into past or present.

- I am contaminated by touching the dirty objects for e.g., dustbin (मैंने कूड़ेदान छु लिया है और मै गन्दा हो चूका हूँ)I have touched the dustbin and I have been contaminated -

- I have touched other objects and they are also contaminated, for e.g., curtains (मैंने घर के परदे छु लिए हैं और वो भी गंदे हो गए हैं)I have touched the curtaind and they have also been contaminated -

- I have touched one of my family members and now he/she is also contaminated, for e.g., his wife (मैंने अपनी बीवी को छु लिया है अब वो भी गन्दी हो गई है। have touched my wife and she has also been (contaminated

\section{Cognitive drill therapy application}

After psychoeducating the patient and creating drill statements, CDT was executed. Patient was asked to imagine object/situation of fear and verbally repeat the drill statements. Each drill statement was taken up for at least 10-15 minutes.

For example:

Patient: "जब मै नाले का कूड़ा देखता हूँ तो लगता है वो मुझे छु गया है और उससे मै गन्दा हो गया हूँ और उससे सब चीज़े गन्दी हो जाएंगी" - "when I see runnel garbage I feel as if it had touched me and I have been contaminated and due to which everything around me will get contaminated"

Drill statement: "नाले का कूड़ा मुझे छु गया है उससे मै गन्दा हो गया हूँ उससे सब चीज़े गन्दी हो गई है" "Runnel garbage had touched me due to which I have been contaminated and everything around me have been contaminated".

Patient: "स्वीपर की गाड़ी मुझे छु जाएगी उससे मै गन्दा हो जाऊंगा"- "Sweeper's cart will touch me due to which I will get contaminated". 
Patient was asked to imagine that his cloths touched the sweepers cart and say Drill statement repeatedly "स्वीपर की गाड़ी मुझे छु चुकी है उससे मै गन्दा हो गया हूँ" - "Sweeper's cart had touched me due to which I have been contaminated".

When the fright for one object or drill statement got abridged the next object or drill statement was picked up. Moment to moment monitoring of body-mind reactions was done by taking the subjective reports of distress by the patient. The patient was asked to report his distress level during the drill. If BMR intensified to high level, pauses of 1-2 minutes were given. When BMR got reduced in pause, the drills were recommenced. Whenever his BMR shoots up modeling was done, in which therapist repeats the drill statements vocally in front of the patient and patient just have to listen to it, which leads to self enabling.

\section{Modeling $\longrightarrow$ Assisted learning $\longrightarrow$ Self enabling}

At the same time drill dilution was also used, in which whenever BMR peaks, we ask the patient to omit keywords that might be causing anxiety and then repeat the drill, while imagining the feared object. With repeatedly performing drill on various feared objects generalization was established for few objects.

\section{Acquisition $\longrightarrow$ Proficiency $\longrightarrow$ Management $\longrightarrow$ Generalization}

With generalization drill compounding was done, in which we mixed more than one feared objects together, and developed a drill statement. Similarly, drill was performed for almost all the object that patient listed as threatening stimuli.

\section{Drill, daring and distraction}

Patient was asked and expected to carry out drill statements whenever he faces a danger object or feels anxious at home. Along with that behavioral experiments were tried, patient was instructed to try to go close or touch the feared objects and get contaminated with them and perform drill statements on his own. Patient was encouraged to keep himself distracted in some fruitful work in the face of anxiety. Patient started remaining comfortable with the feared object after sixth session. Home work was reviewed in the beginning of each session, patient was asked to give subjective report of his fear and how much improvement he feels.

\section{Termination}

Therapy was terminated after eight sessions, when the patient reported minimal anxiety and feeling comfortable in presence of perceived threatening stimuli with minimal or no feared reactions. Psycho education to family members was given. Patient was asked to repeat the drill statements in face of anxiety.

\section{Post Therapy assessment}

In post assessement his scores on Y-BOCS severity rating scale were found to be 10 and 9 for obsessions and compulsions respectively indicating mild level of severity. Patient's score on VOCI-MC after the therapeutic sessions came out to be 22, suggestive of mild level of mental contamination. Patient's score on SDS after the therapeutic session scores were found to be 7 , which indicative of unimpaired global functioning.

\section{Follow up}

Follow up sessions are conducted twice a month, to avoid relapse. Three follow up sessions were conducted till date. Patient reported improvement in all spheres of his life including social, personal and occupational. Patient reported being highly satisfied with the therapy and he is very motivated. Along with that his wife reported considerable improvement in his behavior and symptoms. Further patient brought up some new object of fear which he was not able to do the drill by himself at home; hence drill for the same was conducted. Patient was instructed to practice drill at home by himself as much as possible. Assessment was done after follow up session which was conducted after 2.5months; his scores were found to be 6 and 5 for obsessions and compulsions respectively, indicative of subclinical level of severity.

\section{Results:-}

Pre and post assessment was done through the therapeutic sessions by administering Y-BOCS severity rating scale (Y-BOCS), The Vancouver Obsessional Compulsive Inventory-Mental Contamination Scale (VOCI-MC) and 
Sheehan Disability Scale (SDS). On Y-BOCS rating scale his scores were found to be 20 and 23 for obsessions and compulsions respectively, both indicating moderate level of severity. Post assessement indicated his scores to be 10 and 9 for obsessions and compulsions respectively indicating mild level of severity. Further in the follow up session his scores were found to be 6 and 5 for obsessions and compulsions respectively, indicative of subclinical level of severity. Patient's score on VOCI-MC was found to be 65; it was suggestive of very high level of mental contamination, after the therapeutic sessions scores came out to be 22, suggestive of mild level of mental contamination. Patient's score on SDS was found to be 20 which indicate moderate level of impairement in global functioning. After the therapeutic session scores were found to be 7 , which indicative of unimpaired global functioning.

\section{Other Therapeutic Outcomes}

The application of CDT produced significant changes in the anxiety symptoms of Patient:

- Increased optimism and increased self efficacy.

- Started maintaining good interpersonal relationships.

- He started to understand objects of fear and how to drill to reduce anxiety.

- He is mentally prepared to expose himself to any situation to which previously he was scared of.

- Patient's insight about his illness has also been improved.

- $\quad$ Patient's score on Y-BOCS fell from 43 to 19.

\section{Discussion:-}

Present case study was done to see the efficacy of cognitive drill therapy in OCD. Implementation of CDT on the patient of OCD has brought considerable and noteworthy changes within the patient. Patient reported significant improvement in various areas in which earlier he was facing difficulty. Patient's self confidence and self efficacy has also been enhanced. Through CDT patient was exposed to deeper levels of his perceived danger cognitions. Verbal exposure provides an opportunity to the patient to face his danger thoughts without getting intimidated, in a safe environment, which is also helpful in avoiding dropout. In reality the person is not scared of the object but with the prospect of future outcome, which was getting contaminated in the present case. With the help of repeated verbal and imagined exposure to feared consequences the patient was able to win over his danger thoughts, at the same time he developed self efficacy, in that he realized if such a situation comes in future he would be able to tackle it without getting anxious. He is now able to touch dirty objects without being terrified about the future outcomes and remains comfortable in its presence. With repeated verbal exposure he would be able to tackle some other small danger thoughts that are left. Patient is very motivated and comes for all the follow-up sessions. So far three sessions had been taken up.

\section{Conclusion:-}

The present case work up has indicated the effectiveness of CDT in treating OCD. This call for large scale studies in various anxiety disorders in future to establish its efficacy with confidence. Also longitudinal studies should be conducted to see if its outcomes are maintained over long period of time. Large scale studies comparing cognitive drill therapy with cognitive behavior therapy could be implemented to see procedures and processes involved that make this therapy more superior. Furthermore, an independent evaluator could be employed to assess the outcomes of therapy in a more unbiased way.

\section{References:-}

1. Arya, B., Verma, S., \& Kumar, R. (2017). Efficacy of cognitive drill therapy in treatment of m specific phobia. SIS Journal of Projective Psychology and Mental Health, 24, 48-51.

2. Foa, E. B., Kozak, M. J., Goodman, W.K., Hollander, E., Jenike, M. A., \& Rasmussen, S. A. (1995). DSM-IV field trial: Obsessive-compulsive disorder scale. American Journal of Psychiatry, 152(1), 90-96.

3. Foa, E. B., Kozak, M. J., Salkovskis, P. M., Coles, M. E., \& Amir, N. (1998). The validation of a new obsessive-compulsive disorder scale: The Obsessive-Compulsive Inventory. Psychological Assessment, 10(3), 206-214.

4. Gillihan, S. J., Williams, M. T., Malcoun, E., Yadin, E., \&Foa, E. B. (2012). Common pitfalls in exposure and response prevention (EX/RP) for OCD. Journal of obsessive-compulsive and related disorders, 1(4), $251-257$.

5. Jain, R. (2016). Cognitive drill therapy: fast phobia \& OCD Relief, $1^{\text {st }}$ edition, ISBN-13.

6. Kumar, R., \&Dubey, B. L. (2016). Cognitive Drill Therapy: A Potent Application of the Principles of Psychology for OCD and Phobia. SIS J. of Proj. Psychology and Mental Health, 23(2), 125-126. 
7. Rachman, S. J., \& Hodgson, R. J. (1980). Obsessions and compulsions. Prentice Hall.

8. Sadock, B. J., Sadock, V. A., \& Ruiz, P. (2015). Synopsis of Psychiatry. Vol. 1. Philadelphia: WoltersKluwer, $11,473-5$.

9. Torres, A., Prince, M., Bebbington, P., Bhugra, D., Brugha, T., Farrell, M., et al. (2006). Obsessive-compulsive disorder: prevalence, comorbidity, impact, and help-seeking in the British National Psychiatric Morbidity Survey of 2000. American Journal of Psychiatry, 163, 1978-1985.

10. Warnock-Parkes, E., Salkovskis, P., Rachman, J. (2012). When the problem is beneath the surface in OCD: The cognitive treatment of a case of pure mental contamination. Behavioral and Cognitive Psychotherapy, 40, 383399. 